Jurnal Qua Teknika, Vol. 8 No. 2 September 2018

p-ISSN: 2088-2424; e-ISSN: 2527-3892

Fakultas Teknik Universitas Islam Balitar, Blitar

Http://qua.unisbablitar.ejournal.web.id; Email; quateknika@Gmail.com

Ahmad Ahsanudin Syafawi, Farrady Alif Fiolana, Fajar Yumono. 2018. Prediksi Luas Bangun Berbasis Image Prosessing Algoritma Canny.

Jurnal Qua Teknika, (2018), 8(2) : 31-42

\title{
PREDIKSI LUAS BANGUN BERBASIS IMAGE PROSESSING ALGORITMA CANNY
}

\author{
Ahmad Ahsanudin Syafawi, Farrady Alif Fiolana, Fajar Yumono. \\ Program Studi Teknik Elektro Fakultas Teknik, Universitas Islam Kadiri \\ Jl. Sersan Suharmadji No. 38Kota Kediri Jawa Timur \\ Email : ahsanadik@gmail.com
}

\begin{abstract}
ABSTRAK
Dalam menentukan luas objek persegi, persegi panjang, dan lingkaran diperlukanlah sebuah penggaris untuk mendapatkan nilai luasannya, agar lebih mudah dan praktis dapat dibantu dengan sebuah web camera dengan cara mengcapture gambar sampel objek yang ingin diketahui luasnya. Image Prosessing adalah suatu proses yang digunakan untuk mengolah citra atau gambar untuk mendapatkan citra yang lebih bagus mengunakan perangkat sistem komputer. Untuk mendapatkan perolehan panjang $(\mathrm{X}, \mathrm{Y})$ dari gambar dapat diukur setelah melewati beberapa tahapan di image prosessing yaitu dengan konversi citra dari RGB, HSV dan deteksi tepi canny, lalu terdapatlah nilai luasan dari hasil pengukuran objek. Metode Canny sendiri merupakan deteksi tepi paling baik ketika digunakan untuk mendeteksi tepi objek, sehingga hasil deteksi tepi tersebut dapat diambil informasi yang berguna dari citra tersebut. Dengan pengukuran luas secara manual dan secara otomatis terdapat presentase error kurang lebih 5\%, hasil luas objek tersebut sudah cukup akurat namun terdapat masalah jika dalam pembuatan objek kurang presisi, peletakan objek yang miring/kurang tegap dan pencahayaan yang kurang mengakibatkan kurangnya tingkat akurasi.
\end{abstract}

Kata kunci: Luas Objek, Deteksi Tepi, Canny

\begin{abstract}
In determining the area of a square, rectangle, and circle object a ruler is needed to get the area value, so that it can be easier and more practical to be assisted by a web camera by capturing the image of the object sample that you want to know the area. Image Prosessing is a process used to process images or images to get better images using computer system devices. To get the long gain $(\mathrm{X}, \mathrm{Y})$ from the image can be measured after passing through several stages in image processing that is by image conversion from RGB, HSV and canny edge detection, then there is an area value from the object measurement results. The Canny method itself is the best edge detection when used to detect the edge of an object, so that the useful information of the edge detection can be retrieved from the image. With the area measurement manually and automatically there is a percentage error of approximately 5\%, the object's width results are quite accurate but there is a problem if the object is less precise in making objects, sloping / less robust object laying and less lighting result in a lack of accuracy.
\end{abstract}

Keywords : Object Area, Edge Detection, Canny

\section{PENDAHULUAN}

Dalam kehidupan sehari-hari kita sering mendapati bangun - bangun yang berbentuk persegi, persegi panjang dan bulat/lingkaran, untuk mengukur luas suatu bangun tersebut saat ini masih belum adanya alat untuk menghitung luas objek secara praktis kebanyakkan masih menggunakan cara manual dengan penggaris untuk menentukan luasnya. Dengan menggunakan kamera dapat mengcapture gambar sampel objek yang ingin diketahui luasya, sehingga dapat menentukan panjang, dan lebar (ukuran). Kamera merupakan alat bantu utama dalam image prosessing, karena dengan adanya kamera, image prosessing dapat dengan mudah mengambil data setiap objek yang perlu diteliti sesuai dengan luas asli dan dimasukkan dalam program dan selanjutnya melakukan proses image prosessing (pengolahan citra digital).

Image Prosessing (pengolahan citra digital) adalah suatu proses yang digunakan untuk mengola citra atau gambar untuk mendapatkan citra yang lebih bagus mengunakan perangkat sistem komputer. Berdasarkan uraian tersebut maka peneliti akan merancang sebuah sistem otomatis yang dapat menentukan luas objek dengan menggunakan image prosessing yang dapat membantu memberikan solusi atas permasalahan tersebut. Untuk menentukan luas objek agar lebih mudah dan praktis. 
Jurnal Qua Teknika, Vol. 8 No. 2 September 2018

p-ISSN: 2088-2424; e-ISSN: 2527-3892

Fakultas Teknik Universitas Islam Balitar, Blitar

Http://qua.unisbablitar.ejournal.web.id; Email; quateknika@Gmail.com

Ahmad Ahsanudin Syafawi, Farrady Alif Fiolana, Fajar Yumono. 2018. Prediksi Luas Bangun Berbasis Image Prosessing Algoritma Canny.

Jurnal Qua Teknika, (2018), 8(2) : 31-42

\section{Web Camera}

Layaknya kamera pada umumnya, sebuah webcam dapat mengirimkan gambar-gambar secara live dari manapun ia berada ke seluruh penjuru dunia dengan bantuan internet. Awal kemunculannya, webcam ini masih merupakan barang mahal. Tapi, seiring dengan kemajuan teknologi, sudah banyak laptop yang layarnya telah dilengkapi oleh webcam. Untuk komputer, jarang ada yang secara default dilengkapi dengan webcam, pemilik komputer harus membelinya terlebih dahulu secara terpisah.

\section{Pixel}

Pixel (Picture Elements) adalah nilai setiap entri matriks pada bitmap. Rentang nilai-nilai pixel ini dipengaruhi oleh banyaknya warna yang dapat ditampilkan. Jika suatu bitmap dapat menampilkan 256 warna maka nilai-nilai pixelnya dibatasi dari 0 hingga 255 . Suatu bitmap dianggap mempunyai ketepatan yang tinggi jika dapat menampilkan lebih banyak warna. Prinsip ini dapat dilihat dari contoh pada gambar 1 yang memberikan contoh dua buah bitmap dapat memiliki perbedaan dalam menangani transisi warna putih ke warna hitam.

\section{Deteksi Tepi (Edge Detection)}

Deteksi tepi (edge detection) merupakan salah satu operasi dasar dalam pengolahan citra digital. Deteksi tepi merupakan langkah pertama untuk melingkupi informasi di dalam citra. Tepi mencirikan batas-batas objek dan karena itu tepi berguna untuk proses segmentasi dan identifikasi objek di dalam citra deteksi tepi pada suatu citra.

\section{Canny Edge Detection}

Canny edge detector dikembangkan oleh John F. Canny pada tahun 1986 dan menggunakan algoritma multitahap untuk mendeteksi berbagai tepi dalam gambar. Walaupun metode tersebut telah berumur cukup lama, namun metode tersebut telah menjadi metode deteksi tepi standar dan masih dipakai dalam penelitan.

\section{Segmentasi Warna dengan Deteksi Warna $\mathrm{HSV}$}

Pada metode segmentasi dengan deteksi warna $H S V$ dilakukan pemilihan sampel piksel sebagai acuan warna untuk membentuk segmen yang diinginkan. Citra digital menggunakan model warna $R G B$ sebagai standart acuan warna, oleh karena itu proses awal pada metode ini yang memerlukan konversi model warna dan $H S V$. Untuk membentuk segmen sesuai dengan warna yang diinginkan maka ditentukan nilai toleransi pada setiap dimensi warna $H S V$, kemudian nilai toleransi tersebut digunakan dalam perhitungan proses adaptive threshold. Hasil dari proses threshold tersebut akan membentuk segmen area dengan warna sesuai toleransi yang diinginkan.

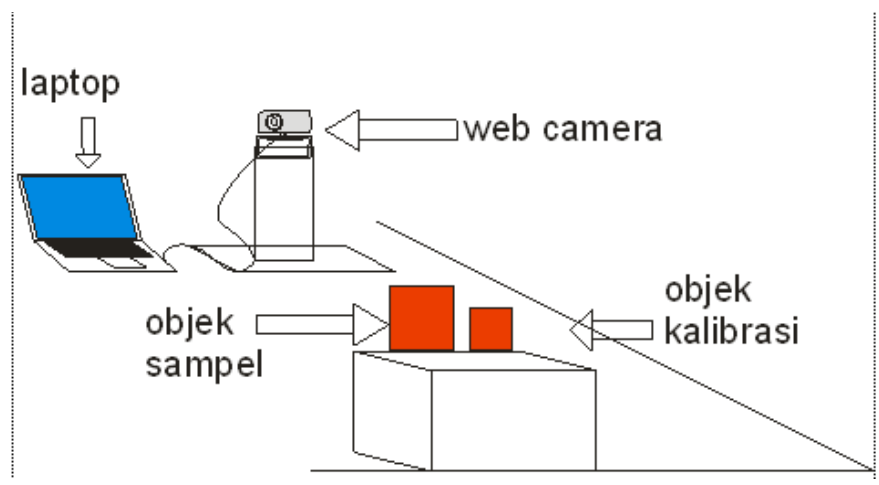

Gambar 1. Sketsa Alat Warna Merah

\section{Pengenalan Pola}

Pengenalan pola merupakan sebuah metode yang telah lama ada dan terus berkembang hingga saat ini. Pengenalan pola tradisional masih berbasis pada kemampuan alat indera manusia. Manusia mampu mengingat suatu informasi pola secara menyeluruh hanya dengan berdasarkan sebagian informasi yang tersimpan dalam ingatannya. 
Jurnal Qua Teknika, Vol. 8 No. 2 September 2018

p-ISSN: 2088-2424; e-ISSN: 2527-3892

Fakultas Teknik Universitas Islam Balitar, Blitar

Http://qua.unisbablitar.ejournal.web.id; Email; quateknika@Gmail.com

Ahmad Ahsanudin Syafawi, Farrady Alif Fiolana, Fajar Yumono. 2018. Prediksi Luas Bangun Berbasis Image Prosessing Algoritma Canny.

Jurnal Qua Teknika, (2018), 8(2) : 31-42

\section{METODE PENELITIAN}

Perancangan dan pembuatan alat untuk prediksi luas objek yang terdiri dari dua bagian utama, meliputi perancangan perangkat keras dan perancangan perangkat lunaknya. Perangkat keras meluputi pemilihan kamera Laptop/webcam yang akan digunakan, dan tiga bentuk sampel sebagai alat ujinya. Sedangkan dalam perancangan perangkat lunaknya menggunakan aplikasi Python 2.7 dan OpenCV.

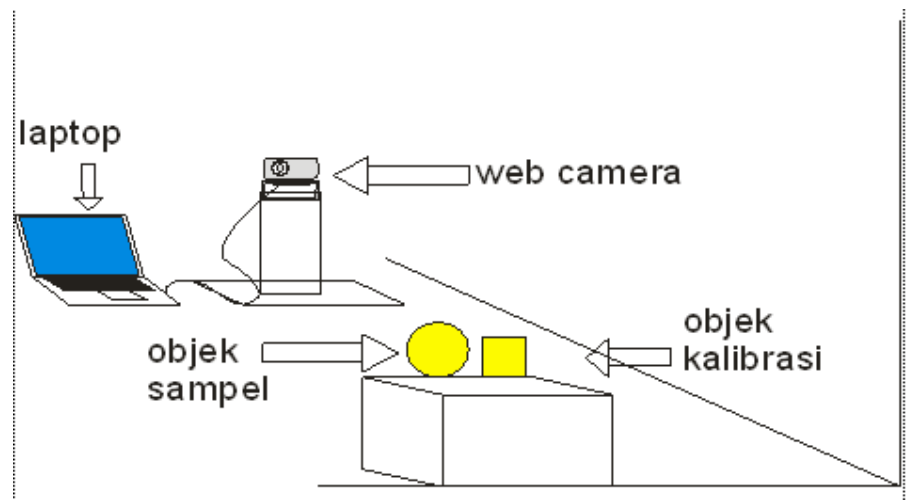

Gambar 2. Sketsa Alat Warna Kuning

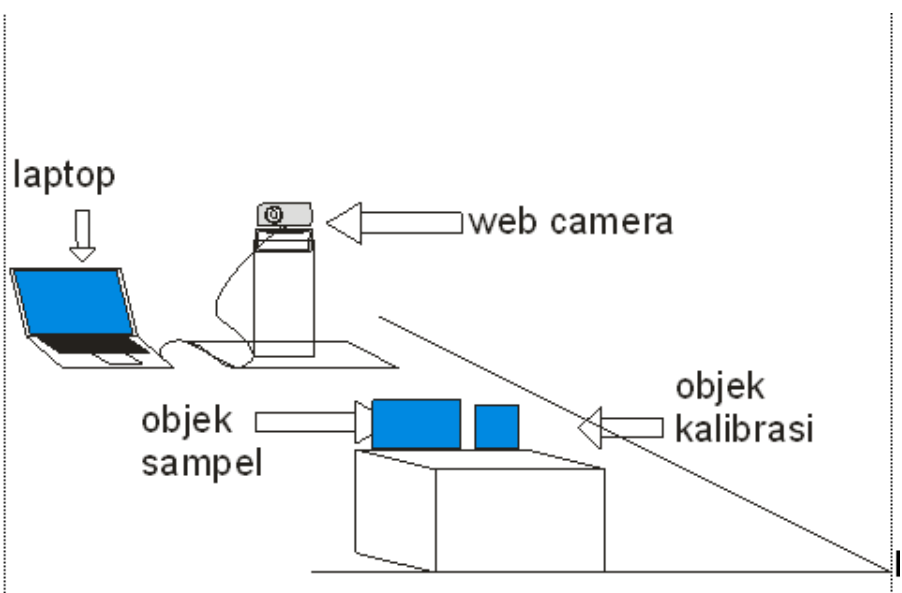

Gambar 3. Sketsa Alat Warna Biru

\section{Perancangan Hardware}

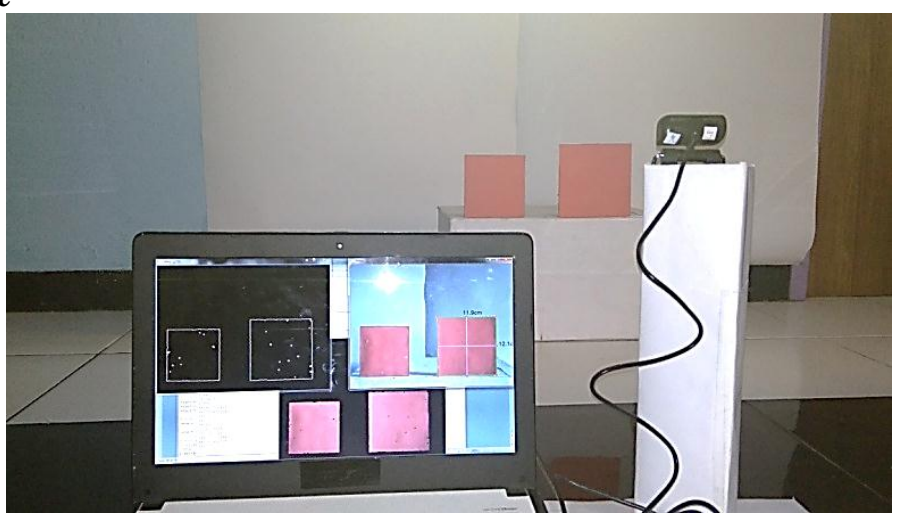

Gambar 4. Peletakan Web Camera dan Objek Sampel Uji 
Jurnal Qua Teknika, Vol. 8 No. 2 September 2018

p-ISSN: 2088-2424; e-ISSN: 2527-3892

Fakultas Teknik Universitas Islam Balitar, Blitar

Http://qua.unisbablitar.ejournal.web.id; Email; quateknika@Gmail.com

Ahmad Ahsanudin Syafawi, Farrady Alif Fiolana, Fajar Yumono. 2018. Prediksi Luas Bangun Berbasis Image Prosessing Algoritma Canny.

Jurnal Qua Teknika, (2018), 8(2) : 31-42

Pada tahap ini merupakan gambaran alat yang nantinya akan diuji, dari perancangan ini diketahui bahwa letak sampel objek pada posisi datar tidak bengkok/miring ke samping, hal itu dikarenakan berkaitan dengan hasil yang diinginkan.

Bagian ini merupakan tahap awal dari penelitian. Pada bagian ini akan membahas tentang garis besar prosessing yang di lakukan terhadap sampel citra.

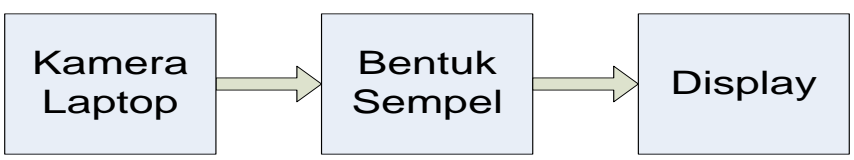

Gambar 5. Diagram Blok Hardware

Dalam perancangan ini peneliti menggunakan Web Camera sebagai alat utama dalam mengambil citra dari objek uji. Lalu Web Camera yang telah mengambil citra pada gambar objek akan mendeteksi nilai $R G B$, warna yang telah dimasukkan di program pada Web Camera maka akan terlebih dahulu di ubah menjadi nilai $H S V$ yang diinginkan. Alat uji yang digunakan adalah gambar berbentuk persegi, persegi panjang, dan lingkaran, yang akan di tampilkan kedalam layar laptop sebagai frame yang sedang peneliti cari dalam menentukan luas tersebut.

\section{Perancangan Software}

Perancangan perangkat lunak pada penelitian ini meliputi perancangan perangkat lunak untuk pengolahan citra yang dilakukan oleh perangkat laptop, serta perangkat lunak untuk deteksi luas objek.

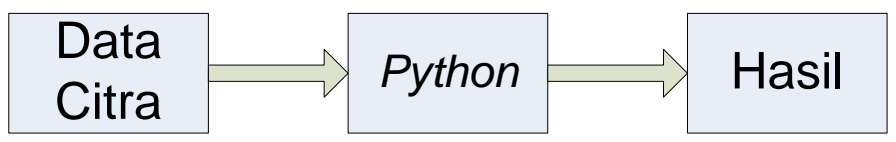

Gambar 6. Diagram Blok Software

Program untuk pengolaha citra pada perangkat laptop dibangun dengan bahasa pemrograman yang telah dilengkapi dengan Library pengolahan citra digital openCV series 3. Software aplikasi yang digunakan untuk mengetikkan pemrograman adalah python 2.7 .

\section{Pengambilan Data}

Langkah-langkah penelitian tahap awal/preprocessing yang dilakukan yaitu pertama citra objek diproses menggunakan $H S V$ dan canny. Hasil dari proses akan menghasilkan beberapa citra hasil deteksi tepi. Hasil akhir berupa hasil perhitungan. Metode Penelitian ditunjukkan seperti Gambar 7.

\section{HASIL DAN PEMBAHASAN}

pada pengujian ini yang dilakuan meliputi pengukuran terhadap parameter-parameter input/masukan proses serta output/keluaran yang terdapat dalam sistem yang dirancang dan tahap-tahapannya pengambilan citra, tahap konversi citra $R G B$ ke $H S V$ dan ke deteksi tepi canny, hingga tahap perhitungan prediksi luas kemudian dilanjutkan dengan menganalisis hasil-hasil pengukuran tersebut.

\section{Pengujian Pengambilan Citra Objek}

Pengujian ini dilakukan untuk mendapatkan parameter-parameter system kerja dari setiap masukan. Citra masukkan yang diperoleh dari web camera yang ditampilkan dan diolah. Contoh pengambilan citra pada tiga bentuk sampel objek yang berbeda terlampir pada gambar 8 . 
Jurnal Qua Teknika, Vol. 8 No. 2 September 2018

p-ISSN: 2088-2424; e-ISSN: 2527-3892

Fakultas Teknik Universitas Islam Balitar, Blitar

Http://qua.unisbablitar.ejournal.web.id; Email; quateknika@Gmail.com

Ahmad Ahsanudin Syafawi, Farrady Alif Fiolana, Fajar Yumono. 2018. Prediksi Luas Bangun Berbasis Image Prosessing Algoritma Canny.

Jurnal Qua Teknika, (2018), 8(2) : 31-42

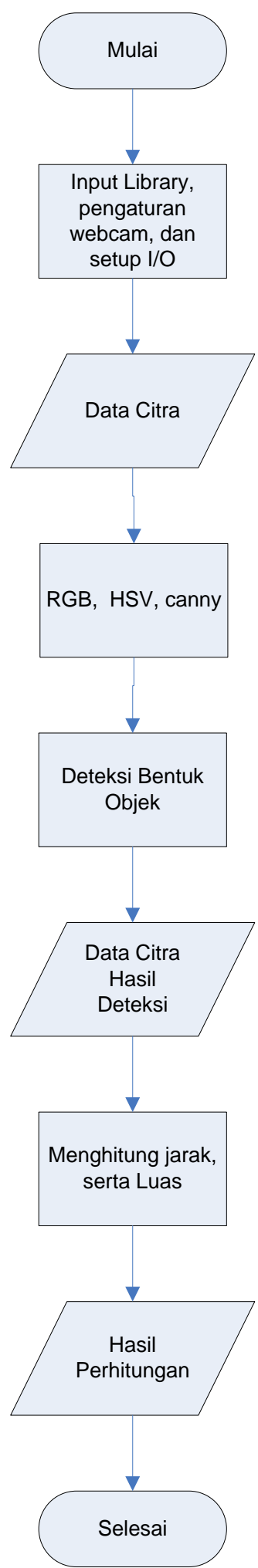

Gambar 7. Flowchart Pengambilan Data 
Jurnal Qua Teknika, Vol. 8 No. 2 September 2018

p-ISSN: 2088-2424; e-ISSN: 2527-3892

Fakultas Teknik Universitas Islam Balitar, Blitar

Http://qua.unisbablitar.ejournal.web.id; Email; quateknika@Gmail.com

Ahmad Ahsanudin Syafawi, Farrady Alif Fiolana, Fajar Yumono. 2018. Prediksi Luas Bangun Berbasis Image Prosessing Algoritma Canny.

Jurnal Qua Teknika, (2018), 8(2) : 31-42

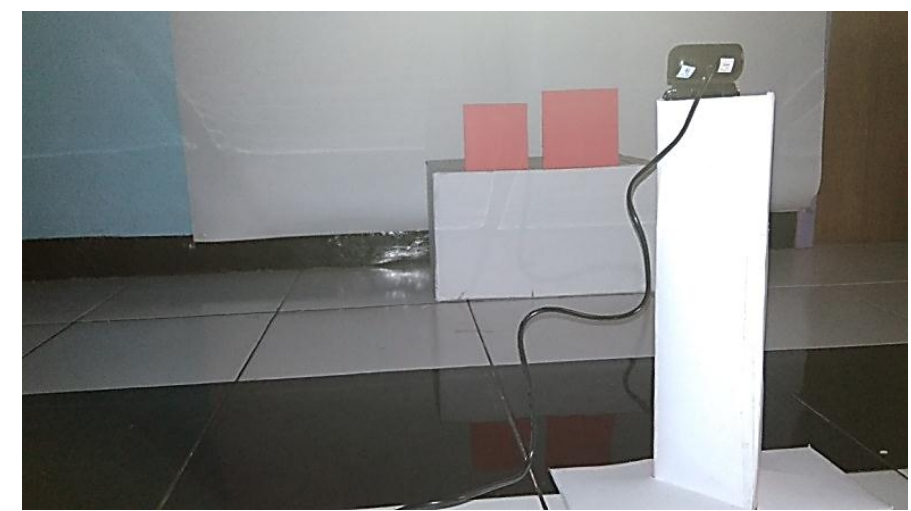

(a) Warna Merah Persegi

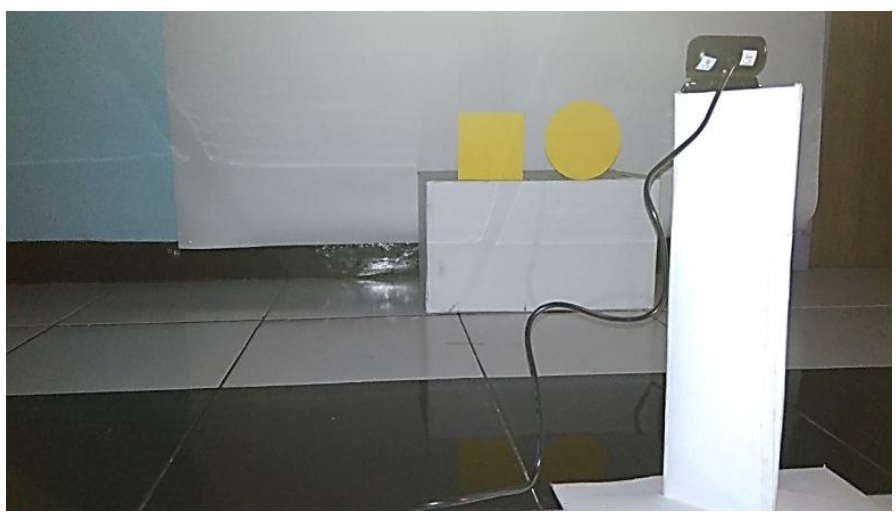

(b)

Warna Kuning Lingkaran

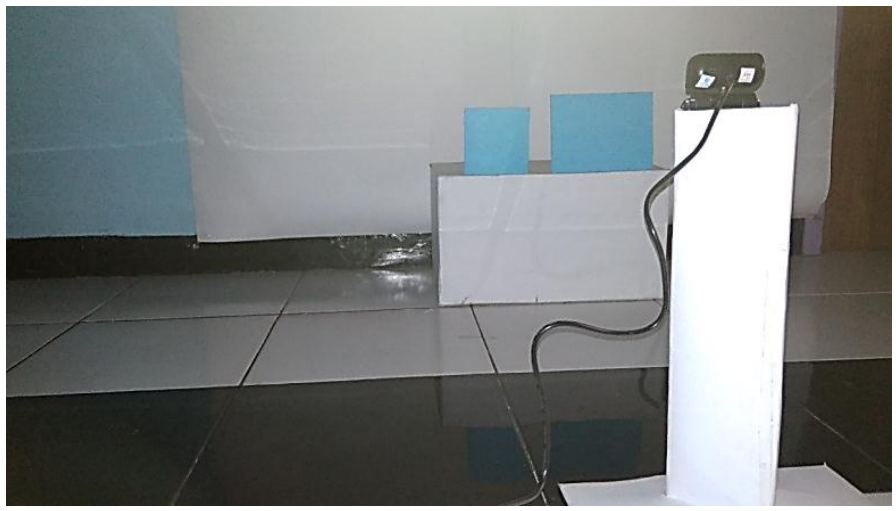

(c) Warna Biru Persegi Panjang

Gambar 8. Posisi Pengambilan Data

Dari sampel bentuk serta warna objek yang berbeda diatas dapat diketahui ukuran pada objek yang berbedabeda, hal ini dikarenankan agar program dapat menentukan luas dari luas bentuk objek yang berbeda. 
Jurnal Qua Teknika, Vol. 8 No. 2 September 2018

p-ISSN: 2088-2424; e-ISSN: 2527-3892

Fakultas Teknik Universitas Islam Balitar, Blitar

Http://qua.unisbablitar.ejournal.web.id; Email; quateknika@Gmail.com

Ahmad Ahsanudin Syafawi, Farrady Alif Fiolana, Fajar Yumono. 2018. Prediksi Luas Bangun Berbasis Image Prosessing Algoritma Canny.

Jurnal Qua Teknika, (2018), 8(2) : 31-42

\section{Parameter Canny dan HSV}

Tabel 1. $R G B$ ke $H S V$ ke Deteksi Tepi

(a) Warna Merah

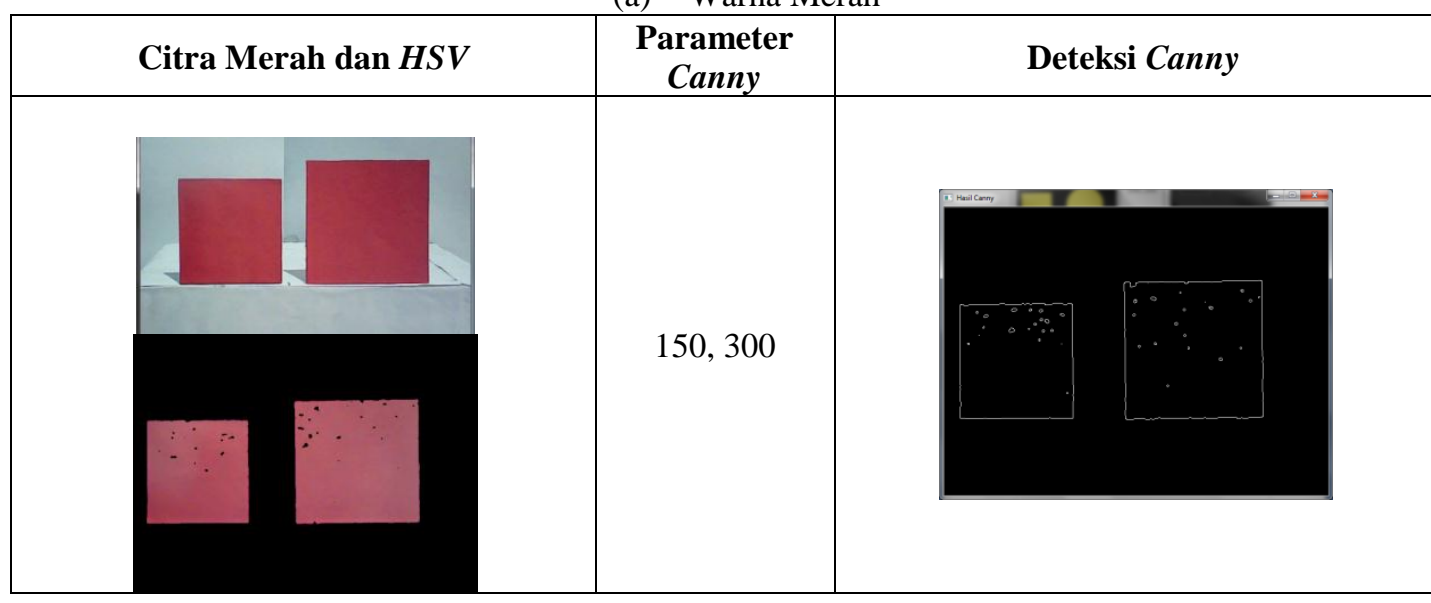

(b) Warna Kuning

\begin{tabular}{|l|c|c|}
\hline \multicolumn{2}{|c|}{ Citra Kuning dan $H S V$} & $\begin{array}{c}\text { Parameter } \\
\text { Canny }\end{array}$ \\
\hline & 150,300 & Deteksi Canny \\
\hline
\end{tabular}

(c) Warna Biru

\begin{tabular}{|l|c|c|}
\hline \multicolumn{1}{|c|}{ Citra Biru dan $\mathrm{HSV}$} & $\begin{array}{c}\text { Parameter } \\
\text { Canny }\end{array}$ & Deteksi Canny \\
\hline & & \\
\hline
\end{tabular}

Berdasarkan Tabel 1. citra RGB ke HSV sebelum dikonversikan ke deteki tepi canny terlihatlah pixel dari $H S V$ yang telah di capture, terdapat noise yang berada pada gambar yang telah di capture dari web camera. 
Jurnal Qua Teknika, Vol. 8 No. 2 September 2018

p-ISSN: 2088-2424; e-ISSN: 2527-3892

Fakultas Teknik Universitas Islam Balitar, Blitar

Http://qua.unisbablitar.ejournal.web.id; Email; quateknika@Gmail.com

Ahmad Ahsanudin Syafawi, Farrady Alif Fiolana, Fajar Yumono. 2018. Prediksi Luas Bangun Berbasis Image Prosessing Algoritma Canny.

Jurnal Qua Teknika, (2018), 8(2) : 31-42

Tabel 2. Hasil warna $H S V$

\begin{tabular}{|c|c|c|}
\hline Warna Yang Di Uji & Parameter $\mathrm{HSV}$ & Warna $H S V$ \\
\hline & $\begin{array}{l}\text { Lower_red } \\
(136,8 \overline{7}, 111) \\
\text { Upper_red } \\
(180,255,255)\end{array}$ & \\
\hline & $\begin{array}{l}\text { Lower_yellow } \\
(22,60,200) \\
\text { Upper_yellow } \\
(60,255,255)\end{array}$ & \\
\hline & $\begin{array}{l}\text { Lower_blue } \\
(90,100,145) \\
\text { Upper_blue } \\
(120,255,255)\end{array}$ & \\
\hline
\end{tabular}

Dari tabel 2 didapatkan hasil bahwa pada wilayah objek dengan menggunakan web camera yang di dapat hanyalah warna $H S V$ yang diinginkan, sedangkan gambar yang berwarna selain warna $H S V$ yang diinginkan tidak terlihat dalam tampilan. Maka citra $H S V$ yang di dapat digunakan untuk proses selanjutnya dalam menghitung luas objek, karena yang didapat hanya warna HSV yang diinginkan, maka dalam tahapan selanjutnya akan dilakukan mendeteksi objek serta luas objek.

\section{Hasil Pengujian Luas}

Pada pengujian sistem secara keseluruhan hasil akan didapatkan setelah web camera mendapatkan frame dari sebuah objek sampel.

Tabel 3. Data Hasil Luas Bangun Persegi Warna Merah

\begin{tabular}{|c|c|c|c|c|c|c|c|}
\hline \multirow{3}{*}{ Sampel } & $\begin{array}{c}\text { Jarak } \\
(\mathrm{cm})\end{array}$ & $\begin{array}{c}\text { Pixel per } \\
\text { metric } \\
\text { Kalibrasi }\end{array}$ & $\begin{array}{c}\text { Object } \\
-\begin{array}{c}\text { width } \\
\text { Uji }\end{array}\end{array}$ & Pixel & $\begin{array}{c}\text { Ukuran } \\
\text { Luas Real } \\
(\mathrm{cm})\end{array}$ & $\begin{array}{c}\text { Ukuran } \\
\text { Luas Uji } \\
(\mathrm{cm})\end{array}$ & Error \\
\hline \multirow{5}{*}{1} & 60 & 49,9 & 154 & 24024 & 64 & 62,3 & $2,7 \%$ \\
\cline { 2 - 8 } & 90 & 33,6 & 103 & 10712 & 64 & 61,3 & $4,2 \%$ \\
\cline { 2 - 8 } & 120 & 24,2 & 74 & 5627 & 64 & 61,8 & $3,4 \%$ \\
\cline { 2 - 8 } & 150 & 19,5 & 61 & 3721 & 64 & 63.1 & $1,4 \%$ \\
\hline \multirow{5}{*}{2} & 180 & 15,9 & 50 & 2600 & 64 & 66,7 & $4,4 \%$ \\
\cline { 2 - 8 } & 60 & 50 & 193 & 38030 & 100 & 98,1 & $1,9 \%$ \\
\cline { 2 - 8 } & 120 & 24,4 & 95 & 9120 & 100 & 99,1 & $0,9 \%$ \\
\cline { 2 - 8 } & 150 & 20,3 & 77 & 6160 & 100 & 96,7 & $4,7 \%$ \\
\cline { 2 - 8 } & 180 & 15,9 & 63 & 3969 & 100 & 101,3 & $1,3 \%$ \\
\hline \multirow{3}{*}{3} & 60 & 49,9 & 232 & 54527 & 144 & 141,4 & $1,8 \%$ \\
\cline { 2 - 8 } & 90 & 33,9 & 158 & 24964 & 144 & 140,6 & $2,4 \%$ \\
\cline { 2 - 8 } & 120 & 24,6 & 115 & 13399 & 144 & 142,6 & $1 \%$ \\
\hline
\end{tabular}


Jurnal Qua Teknika, Vol. 8 No. 2 September 2018

p-ISSN: 2088-2424; e-ISSN: 2527-3892

Fakultas Teknik Universitas Islam Balitar, Blitar

Http://qua.unisbablitar.ejournal.web.id; Email; quateknika@Gmail.com

Ahmad Ahsanudin Syafawi, Farrady Alif Fiolana, Fajar Yumono. 2018. Prediksi Luas Bangun Berbasis Image Prosessing Algoritma Canny.

Jurnal Qua Teknika, (2018), 8(2) : 31-42

\begin{tabular}{|c|c|c|c|c|c|c|c|}
\hline \multirow{4}{*}{} & 150 & 19,6 & 94 & 8648 & 144 & 144,9 & $0,6 \%$ \\
\cline { 2 - 8 } & 180 & 16,2 & 75 & 5775 & 144 & 142,8 & $0,8 \%$ \\
\hline \multirow{4}{*}{4} & 60 & 49,8 & 271 & 74529 & 196 & 194,3 & $0,8 \%$ \\
\cline { 2 - 8 } & 90 & 33,9 & 184 & 34040 & 196 & 191,7 & $2,2 \%$ \\
\cline { 2 - 8 } & 120 & 24,6 & 136 & 18429 & 196 & 196,2 & $0,001 \%$ \\
\cline { 2 - 8 } & 150 & 20 & 112 & 12329 & 196 & 198,6 & $0,1 \%$ \\
\hline \multirow{6}{*}{5} & 180 & 15,9 & 88 & 8008 & 196 & 204,4 & $4,3 \%$ \\
\cline { 2 - 8 } & 60 & 50,3 & 311 & 96721 & 256 & 247,1 & $3,5 \%$ \\
\cline { 2 - 8 } & 120 & 24,6 & 156 & 24417 & 256 & 259,9 & $2,1 \%$ \\
\cline { 2 - 8 } & 150 & 20,1 & 127 & 16075 & 256 & 255,6 & $0,2 \%$ \\
\cline { 2 - 8 } & 180 & 16,2 & 103 & 10609 & 256 & 262,3 & $2,5 \%$ \\
\hline
\end{tabular}

Dari tabel 3 didapatkan hasil bahwa pada objek persegi warna merah dalam pegukuran secara otomatis dengan menggunakan web camera di dapat nilai-nlai yang sudah mendekati nilai luasan aktual. Dengan presentase error (kurang dari 5\%) ada salah satu sampel objek yang hampir sama dengan nilai luasan aktual dengan presentase error $0,001 \%$, dan yang paling tinggi $4,7 \%$. Hal ini membuktikan bahwa dalam pengukuran secara otomatis hampir menemukan nilai yang presisi dan cukup akurat.

Tabel 4. Data Hasil Luas Bangun Lingkaran Warna Kuning

\begin{tabular}{|c|c|c|c|c|c|c|c|}
\hline Sampel & $\begin{array}{c}\text { Jarak } \\
(\mathrm{cm})\end{array}$ & $\begin{array}{l}\text { Pixel per } \\
\text { metric } \\
\text { Kalibrasi }\end{array}$ & $\begin{array}{c}\text { Object } \\
\text {-width } \\
\mathrm{Uji}\end{array}$ & Pixel & $\begin{array}{c}\text { Ukuran } \\
\text { Luas Real } \\
(\mathrm{cm})\end{array}$ & $\begin{array}{c}\text { Ukuran } \\
\text { Luas Uji } \\
(\mathrm{cm})\end{array}$ & Error \\
\hline \multirow{5}{*}{1} & 60 & 50,9 & 155 & 18859 & 50,24 & 46,9 & $6,6 \%$ \\
\hline & 90 & 33,6 & 102 & 18167 & 50,24 & 46,7 & $7 \%$ \\
\hline & 120 & 24,9 & 77 & 4654 & 50,24 & 48,5 & $3,5 \%$ \\
\hline & 150 & 19,7 & 62 & 3017 & 50,24 & 49,9 & $0,7 \%$ \\
\hline & 180 & 15,6 & 50 & 1962 & 50,24 & 51,8 & $3,1 \%$ \\
\hline \multirow{5}{*}{2} & 60 & 51,4 & 193 & 29372 & 78,5 & 71,7 & $8,7 \%$ \\
\hline & 90 & 32,9 & 131 & 13578 & 78,5 & 80,7 & $2,8 \%$ \\
\hline & 120 & 24,9 & 96 & 7329 & 78,5 & 76,4 & $2,7 \%$ \\
\hline & 150 & 20 & 79 & 4899 & 78,5 & 79,02 & $0,7 \%$ \\
\hline & 180 & 15,6 & 63 & 3115 & 78,5 & 82,2 & $4,7 \%$ \\
\hline \multirow{5}{*}{3} & 60 & 51,3 & 232 & 42452 & 113,04 & 104,2 & $7,8 \%$ \\
\hline & 90 & 33,3 & 153 & 18499 & 113,04 & 107,4 & $5 \%$ \\
\hline & 120 & 24,9 & 114 & 10201 & 113,04 & 106,4 & $5,9 \%$ \\
\hline & 150 & 20 & 92 & 6644 & 113,04 & 107,2 & $5,2 \%$ \\
\hline & 180 & 15,9 & 76 & 4534 & 113,04 & 115,8 & $2,4 \%$ \\
\hline 4 & 60 & 51 & 272 & 58077 & 153,86 & 143,9 & $6,5 \%$ \\
\hline
\end{tabular}


Jurnal Qua Teknika, Vol. 8 No. 2 September 2018

p-ISSN: 2088-2424; e-ISSN: 2527-3892

Fakultas Teknik Universitas Islam Balitar, Blitar

Http://qua.unisbablitar.ejournal.web.id; Email; quateknika@Gmail.com

Ahmad Ahsanudin Syafawi, Farrady Alif Fiolana, Fajar Yumono. 2018. Prediksi Luas Bangun Berbasis Image Prosessing Algoritma Canny.

Jurnal Qua Teknika, (2018), 8(2) : 31-42

\begin{tabular}{|c|c|c|c|c|c|c|c|}
\hline \multirow{5}{*}{} & 90 & 33,1 & 184 & 26576 & 153,86 & 156,7 & $1,8 \%$ \\
\cline { 2 - 8 } & 120 & 24,5 & 134 & 14095 & 153,86 & 151,6 & $1,5 \%$ \\
\cline { 2 - 8 } & 150 & 20 & 108 & 9156 & 153,86 & 147,5 & $4,1 \%$ \\
\cline { 2 - 8 } & 180 & 15,9 & 89 & 6217 & 153,86 & 158,7 & $3,1 \%$ \\
\hline \multirow{5}{*}{5} & 60 & 50,8 & 308 & 74468 & 200,96 & 186,4 & $7,2 \%$ \\
\cline { 2 - 8 } & 90 & 33,3 & 211 & 34948 & 200,96 & 202,9 & $1 \%$ \\
\cline { 2 - 8 } & 120 & 24,9 & 153 & 18374 & 200,96 & 191,6 & $4,7 \%$ \\
\cline { 2 - 8 } & 150 & 20 & 127 & 12661 & 200,96 & 204,2 & $1,6 \%$ \\
\cline { 2 - 8 } & 180 & 16,4 & 103 & 8385 & 200,96 & 200,9 & $0,03 \%$ \\
\hline
\end{tabular}

Dari tabel 4 didapatkan hasil bahwa pada objek lingkaran warna kuning dalam pegukuran secara otomatis dengan menggunakan web camera di dapat nilai-nlai yang sudah mendekati nilai luasan aktual. Dengan presentase error salah satunya yang lebih dari (5\%) yakni pada sampel ke 3 jarak $60 \mathrm{~cm}$ dengan jumlah error $7,8 \%$ dikarenakan peletakannya yang kurang tegap dapat menimbulkan error dan pencahayaan yang kemungkinan terlalu terang, sebab warna kuning dapat dengan mudah mendapatkan cahaya, jadi kalau kelebihan cahaya akan mendapatkan error, ada salah satu sampel objek yang hampir sama dengan nilai luasan aktual dengan presentase error $0,03 \%$. Hal ini membuktikan bahwa dalam pengukuran secara otomatis hampir menemukan nilai yang presisi dan cukup akurat.

Tabel 5. Data Hasil Luas Bangun Persegi Panjang Warna Biru

\begin{tabular}{|c|c|c|c|c|c|c|c|}
\hline Sampel & $\begin{array}{c}\text { Jarak } \\
(\mathrm{cm})\end{array}$ & $\begin{array}{c}\text { Pixel per } \\
\text { metric } \\
\text { Kalibrasi }\end{array}$ & $\begin{array}{c}\text { Object } \\
\text { width } \\
\mathrm{Uji}\end{array}$ & Pixel & $\begin{array}{c}\text { Ukuran } \\
\text { Luas Real } \\
(\mathrm{cm})\end{array}$ & $\begin{array}{c}\text { Ukuran } \\
\text { Luas Uji } \\
(\mathrm{cm})\end{array}$ & Error \\
\hline \multirow{5}{*}{1} & 60 & 50,8 & 231 & 36498 & 96 & 91,4 & $4,8 \%$ \\
\hline & 90 & 33,9 & 155 & 16407 & 96 & 92,4 & $3,8 \%$ \\
\hline & 120 & 24,1 & 115 & 8972 & 96 & 99,6 & $3,8 \%$ \\
\hline & 150 & 18,9 & 91 & 5369 & 96 & 96,2 & $0,2 \%$ \\
\hline & 180 & 16,2 & 74 & 3848 & 96 & 95,1 & $0,9 \%$ \\
\hline \multirow{5}{*}{2} & 60 & 50,8 & 271 & 53399 & 140 & 133,7 & $4,5 \%$ \\
\hline & 90 & 33,9 & 184 & 24104 & 140 & 135,7 & $3,1 \%$ \\
\hline & 120 & 24,4 & 136 & 13192 & 140 & 143,4 & $2,4 \%$ \\
\hline & 150 & 19,2 & 107 & 8027 & 140 & 139,9 & $0,07 \%$ \\
\hline & 180 & 15,9 & 89 & 5742 & 140 & 146,6 & $4,7 \%$ \\
\hline \multirow{5}{*}{3} & 60 & 50 & 302 & 70366 & 192 & 181,6 & $5,4 \%$ \\
\hline & 90 & 33,1 & 209 & 32894 & 192 & 193,9 & $1 \%$ \\
\hline & 120 & 24,1 & 155 & 17980 & 192 & 199,7 & $4 \%$ \\
\hline & 150 & 19,5 & 123 & 11488 & 192 & 195,2 & $1,7 \%$ \\
\hline & 180 & 16,2 & 103 & 8034 & 192 & 198,6 & $3,4 \%$ \\
\hline \multirow{2}{*}{4} & 60 & 50,5 & 340 & 93160 & 252 & 235,6 & $6,5 \%$ \\
\hline & 90 & 33,6 & 235 & 43244 & 252 & 247,3 & $1,7 \%$ \\
\hline
\end{tabular}


Jurnal Qua Teknika, Vol. 8 No. 2 September 2018

p-ISSN: 2088-2424; e-ISSN: 2527-3892

Fakultas Teknik Universitas Islam Balitar, Blitar

Http://qua.unisbablitar.ejournal.web.id; Email; quateknika@Gmail.com

Ahmad Ahsanudin Syafawi, Farrady Alif Fiolana, Fajar Yumono. 2018. Prediksi Luas Bangun Berbasis Image Prosessing Algoritma Canny.

Jurnal Qua Teknika, (2018), 8(2) : 31-42

\begin{tabular}{|c|c|c|c|c|c|c|c|}
\hline \multirow{5}{*}{} & 120 & 24,6 & 176 & 24271 & 252 & 258,4 & $2,5 \%$ \\
\cline { 2 - 8 } & 150 & 19,5 & 137 & 15207 & 252 & 257,9 & $2,3 \%$ \\
\cline { 2 - 8 } & 180 & 16,2 & 114 & 10374 & 252 & 256,5 & $1,8 \%$ \\
\hline \multirow{5}{*}{5} & 60 & 50 & 386 & 120046 & 320 & 309,8 & $3,2 \%$ \\
\cline { 2 - 8 } & 90 & 32,8 & 261 & 55071 & 320 & 329,8 & $3,1 \%$ \\
\cline { 2 - 8 } & 120 & 24,4 & 195 & 30420 & 320 & 330,7 & $3,3 \%$ \\
\cline { 2 - 8 } & 150 & 19,1 & 153 & 18839 & 320 & 332,1 & $3,8 \%$ \\
\hline
\end{tabular}

Dari tabel 5. didapatkan hasil bahwa pada objek persegi panjang warna biru dalam pegukuran secara otomatis dengan menggunakan web camera di dapat nilai-nlai yang sudah mendekati nilai luasan aktual. Dengan presentase error salah satunya yang lebih dari (5\%) yakni pada sampel ke 4 jarak 60cm dengan jumlah error $6,5 \%$ dikarenakan peletakannya yang kurang tegap dapat menimbulkan error serta warna biru yang membutuhkan pencahyaan yang harus terang, ada salah satu sampel objek yang hampir sama dengan nilai luasan aktual dengan presentase error $0,07 \%$. Hal ini membuktikan bahwa dalam pengukuran secara otomatis hampir menemukan nilai yang presisi dan cukup akurat.

\section{SIMPULAN}

Dari hasil penelitan dan pembahasan tentang alat perhitungan luas otomatis pada objek dengan menggunakan metode deteksi tepi canny yang telah dilakukan dan diuraikan maka dapat disimpulkan bahwa :

1. Citra pada warna objek dapat dibedakan dengan menggunakan beberapa tahapan konversi yang nantinya akan diproses untuk mencari nilai pixel dari gambar. Perolehan panjang $(\mathrm{X}, \mathrm{Y})$ dari gambar dapat diukur setelah melewati beberapa tahapan yaitu dengan citra RGB, HSV dan tedeksi tepi canny lalu didapatlah nilai luasan dari hasil pengukuran objek.

2. Dari hasil perbandingan pengukuran luas objek secara otomatis dengan ukuran real, diperoleh tingkat presentase error (kurang lebih 5\%) dari pengukuran secara otomatis dibandingkan ukuran real, dapat disimpulkan bahwa pengukuran secara otomatis sudah cukup akurat namun terdapat masalah jika dalam peletakan objek dengan yang miring dan pencahayaan yang kurang.

\section{REFERENSI}

[1] Ahmad Mustafid, (2016), "Perancangan Sistem Pengolahan Citra Digital Untuk Menentukan Bobot Sapi Menggunakan Metode Canny Edge Detection", Universitas Islam Negeri Sunan Kalijaga, Yogyakarta.

[2] Rama Okta Wiyagi, dan Muhamad Yusvin Mustar, (2015), "Deteksi Jarak Objek Bercahaya Secara Real Time Menggunakan Kamera Tunggal”, Universitas Muhammadiyah Yogyakarta, Yogyakarta.

[3] RD. Kusumanto, dan Alan Novi Tompunu, (2011), "Pengolahan Citra Digital Untuk Mendeteksi Obyek Menggunakan Pengolahan Warna Model Normalisasi RGB”, Politeknik Negeri Sriwijaya, Palembang.

[4] Ari Kurniawan Saputra, (2016), “Aplikasi Deteksi Objek Menggunakan Histogram Of Oriented Gradient Untuk Modul Sistem Cerdas Pada Robot Nao", Universitas Bandar Lampung, Lampung.

[5] Yustinus Pancasila Prayitno, dkk, (2017), "Rancang Bangun Aplikasi Pendeteksi Bentuk Dan Warna Benda Pada Mobile Robot Berbasis Webcam", STIKOM, Surabaya.

[6] Hepi Hapsari Handayani Sarkawi Jaya Harahap, (2015), "Visualisasi 3D Objek Menggunakan Teknik Fotogrametri Jarak Dekat”, Institut Teknologi Sepuluh Nopember (ITS), Surabaya.

[7] Pelajaran, "Bangun Datar - Pengertian, Macam-Macam, Sifat-Sifat, dan Rumus Bangun Datar Terlengkap", diperoleh dari: www.pelajaran.co.id [diakses 25 Juli 2018].

[8] Danang Erwanto, (2017), "Pemanfaatan Pengolahan Citra Digital Pada Proses Quality Control Pengemasan Primer Obat Dengan Menggunakan Metode Normalisasi Warna”, Tesis Magister, Universitas Islam Sultan Agung, Semarang.

[9] Nesaba Media, "Pengertian Webcam Beserta Fungsi dan Cara Kerja Webcam", diperoleh dari: www.nesabamedia.com [diakses 18 Mei 2018]. 
Jurnal Qua Teknika, Vol. 8 No. 2 September 2018

p-ISSN: 2088-2424; e-ISSN: 2527-3892

Fakultas Teknik Universitas Islam Balitar, Blitar

Http://qua.unisbablitar.ejournal.web.id; Email; quateknika@Gmail.com

Ahmad Ahsanudin Syafawi, Farrady Alif Fiolana, Fajar Yumono. 2018. Prediksi Luas Bangun Berbasis Image Prosessing Algoritma Canny.

Jurnal Qua Teknika, (2018), 8(2) : 31-42

[10] Rika Favoria Gusa, (2013), "Pengolahan Citra Digital untuk Menghitung Luas Daerah Bekas Penambangan Timah", Universitas Bangka Belitung, Bangka Belitung.

[11] Masnun Dasopang, (2015), "Metode Perancangan Pengarangkat Lunak Mereduksi Noise Citra Digital Menggunakan Contraharmonic Mean Filtter", STMIK Budi Darma, Medan.

[12] Arief Yudiyanto, dan Murinto, (2014), "Implementasi Metode Canny Untuk Deteksi Tepi Mutu Daun Tembaka", Universitas Ahmad Dahlan, Yogyakarta.

[13] Jati Sasongko Wibowo, (2011), "Deteksi dan Klasifikasi Citra Berdasarkan Warna Kulit Menggunakan HSV”, Universitas Stikubank, Semarang.

[14] Derisma, (2016) "Faktor-Faktor yang Mempengaruhi Sistem Pengenalan Wajah Menggunakan Metode Eigenface pada Perangkat Mobile Berbasis Android“, Universitas Andalas, Padang.

[15] Therzian Richard Perkasa, Helmy Widyantara, dkk, (2014), "Rancang Bangun Pendeteksi Gerak Menggunakan Metode Image Subtraction Pada Single Board Computer (Sbc)”, STIMIK, STIKOM, Surabaya.

[16] Elektronika Dasar, "Pengertian Citra", diperoleh dari: http://elektronika-dasar.web.id [diakses 18 Juli 2018].

[17]R Dimas Adityo, (2014), "Kalibrasi Parameter Kamera Dengan Menggunakan Projector Untuk Rekonstruksi 3d Berbasis Metode Structured Light", Universitas Bhayangkara, Surabaya.

[18] Wikaria Gazali, Alexander Agung Santoso Gunawan, (2012) “Analisis Dan Pembuatan Sistem Pengenalan Sidik Jari Berbasis Komputer Di Polda Metro Jaya”, Binus University, Jakarta Barat.

[19] Pyimagesearch, "Measuring size of objects in an image with OpenCV", diperoleh dari: www.pyimagesearch.com [diakses 6 Juli 2018].

[20] Danang Erwanto, et al, 2017 IOP Conf. Ser.: Mater. Sci. Eng. 190012043

[21] Bayu Ardianto, (2017) "Pengukur Jarak Objek Menggunakan Pengolahan Citra Dengan Bantuan Laser" Universitas Islam Kadiri, Kediri. 